\title{
A Core Model for Parts Suppliers Selecting Method in Manufacturing Supply Chain
}

\author{
Guorong Chen, ${ }^{1,2,3}$ Jiangyuan Zhao, ${ }^{2}$ and Juli Deng ${ }^{1}$ \\ ${ }^{1}$ School of Electronic and Information Engineering, Chongqing University of Science and Technology, Chongqing 401331, China \\ ${ }^{2}$ CAIA, Dhurakij Pundit University, Bangkok 10210, Thailand \\ ${ }^{3}$ Faculty of Engineering, University of Ottawa, Ottawa, ON, Canada K1N 6M9
}

Correspondence should be addressed to Juli Deng; cwcgr@126.com

Received 3 June 2014; Revised 1 September 2014; Accepted 2 September 2014

Academic Editor: Housheng Su

Copyright (C) 2015 Guorong Chen et al. This is an open access article distributed under the Creative Commons Attribution License, which permits unrestricted use, distribution, and reproduction in any medium, provided the original work is properly cited.

\begin{abstract}
Service-oriented manufacturing is the new development of manufacturing systems, and manufacturing supply chain service is also an important part of the service-oriented manufacturing systems; hence, the optimal selection of parts suppliers becomes one of key problems in the supply chain system. Complex network theories made a rapid progress in recent years, but the classical models such as BA model and WS model can not resolve the widespread problems of manufacturing supply chain, such as the repeated attachment of edge and fixed number of vertices, but edges increased with preferential connectivity, and flexible edges' probability. A core model is proposed to resolve the problem in the paper: it maps the parts supply relationship as a repeatable core; a vertex's probability distribution function integrating the edge's rate and vertex's degree is put forward; some simulations, such as the growth of core, the degree distribution characteristics, and the impacting of parameter, are carried out in our experiments, and the case study is set also. The paper proposed a novel model to analyze the manufacturing supply chain system from the insights of complex network.
\end{abstract}

\section{Introduction}

Manufacturing services spawned the manufacturing system's range, which needs the dominant firms collaborating with their parts suppliers beyond geographical boundaries, but how to select the most optimal parts suppliers in the supply chain becomes the new difficulty. In order to resolve the problem of optimal selecting part suppliers in manufacturing supply chain, many scholars devote their researches in the topics from those fields.

The first field is the cooperation models in the manufacturing supply chain. Holland proposed the mode of cooperation and collaboration of supply chain management [1]; Sarmah et al. went into the coordination models between the business entities to gain lower supply chain cost [2]. Kelle and Akbulut discussed the software tools of ERP in supply chain for information sharing, cooperation, and cost optimization [3]; Nagarajan and Sošić discussed the gametheoretic analysis method in cooperation supply chains [4];
Fiala discussed the information sharing between suppliers, manufacturers, distributors, retailers, and customers [5]; Savaskan et al. discussed the closed loop supply chain models with product remanufacturing [6]; Ma and Chen researched on the elements and characters in integrated logistics' supply chain [7]; Xu and Ma researched on the trust mechanism between enterprises in supply chain and suggested that the cultivation of mutual trust of enterprises is the core of supply chain management [8]; and Love et al. researched on the interorganizational relations in construction industry [9].

The second field is the dynamic analysis, evaluation methods, and the business forecasting in the supply chain. Liang et al. put forward nonlinear programming problems to solve the DEA (Data envelopment analysis) models for supply chain efficiency evaluation [10]; Leng and Zhu reviewed the side-payment contracts in two-person nonzero-sum supply chain games and discussed its application [11]; Zhu et al. researched on the confirmation of a measurement model for green supply chain management practices implementation 
[12]; Cachon and Zipkin discussed the competitive and cooperative inventory policies in a two-stage supply chain [13]; Sarkis proposed a strategic decision framework for green supply chain management [14]; Huang et al. discussed an analysis of manufacturer-retailer supply chain coordination in cooperative advertising [15]; Ferguson discussed the "commitment time frame problem" between an end product manufacturer and a parts supplier [16]; Surana et al. researched the context of supply-chain networks [17]; Gupta and Maranas discussed the managing demand uncertainty method in supply chain planning and proposed a tool for evaluating and actively managing the exposure of enterprises assets (such as inventory levels and profit margins) to market uncertainties [18]; Kim et al. go through an empirical investigation in IT alignment between supply chain partners to enhance customer value creation [19]; and Connelly et al. discussed the perspectives of six prominent organizational theories, such as apply real options theory, internationalization theory, organizational economics, resource dependence theory, social network theory, and institutional theory, and how to effect the development of supply chain [20].

The third field is the complex network analysis approach and its applications. Stanley Milgram pointed out the famous theories of six degrees of separation; he observed that the distant of human in the world is about six degrees; Watts built a special website to check the theories [21]; and game of Kevin Bacon checked the theories as Bacon degree [22], and some scholars in Oakland University go through the theories as Erdos degree [23]; all of those experiments proved the theories are valid. Erdös and Rényi study the social network based on the perspective of graph theory for the first time in the world and published a famous paper on the evolution of random graphs [24]; Watts and Strogatz researched on the modeling of small-world networks, characteristics, and mechanism [25, 26]; Barabási and Albert studied some kinds of complex networks and put forward the statistical mechanism of small world networks, scale-free networks, complex networks, and evolutionary theory [27, 28]; Gregoriades A and Sutcliffe studied the reliability of complex systems based on load forecasting and planning methods [29]. Shi et al. studied the calculation model and vertex degree distribution of complex networks, such as clustering coefficient estimates [30, 31]; Wang research network synchronization and control technology [32]; Li and Chen studied the control principles and methods of complex networks [33]. Guoning and Zheren discussed the components product family relations, described the relationship between the network diagram of parts products using the weighted directed tree network method, calculated the statistical properties of the relationship between the network components, studied the revolution process of the parts products relationship network diagram, and proposed a prediction approach of the amount of parts [34]. The study is completely broken through the traditional way of manufacturing research information system and provides a guideline for our research.

From the reviews above, we can see that the complex network theory and its applications have made a rapid progress in recent years, and it can integrate the system engineering and topology and became a new approach to be

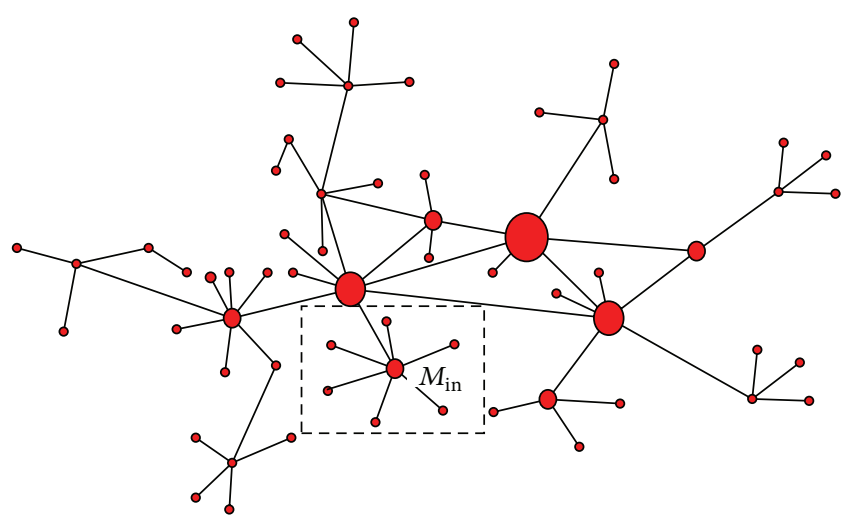

FIGURE 1: The supply relationship network.

used to analyze the part suppliers' optimal selecting problems of manufacturing supply chain.

But there have been rare reports of complex network theories applied in manufacturing supply chain. Based on the preliminary studies [35], this paper will focus on the part supplier's optimal selecting problems and presents a core model for the part suppliers optimal selecting problems in manufacturing supply chain. It will describe the application problem in Section 2; analyze the shortcomings of two classical complex network models named BA model and WS model in Section 3; put forward a core model, discuss the designs and description of the model, and present the probability formula of selecting part suppliers in detail in Section 4; and simulate the model and analyze the characteristics in Section 5 .

\section{The Problem Description}

The supply relationship of parts in manufacturing system intertwined together and formed a complex relationship network. The dominant firm wants some parts for assembling its production. If there are many parts suppliers meeting the given quality and times requirements, the cost is the key factors to affect their decision that those parts suppliers should to be selected. Supposing the parts consisted of some parts, the parts are made up of subparts and so on; the supply relation forms a supply relationship network, so the manufacturing supply chain has the sketch as Figure 1.

It is not easy to resolve the suppliers selecting problem of the whole network. In the paper, we select one vertex that has many suppliers to analyze; other vertices' characteristics are easy to arrive using the same method.

\section{The Relationship Model Researches and the New Characteristics of Manufacturing Supply Chain}

Toward the manufacturing supply chain, the similar researches mainly were two famous models, WS model [25] and BA model [27]. 
3.1. The WS Model [25]. Watts and Strogatz reported the WS model firstly in their "Collective dynamics of 'small-world' networks" in 1998 (by Nature). Newman and Watts improved it as NW model in 1999 [36]. The WS model starts from a ring lattice with $n$ vertices and $k$ edges per vertex then rewire each edge at random with probability $p$. This model shows a graph between regularity $(p=0)$ and disorder $(p=1)$, for intermediate values of $p$, and the graph is a small-world network that is highly clustered like a regular graph, yet with small characteristic path length, like a random graph; it is shown in Figure 2. The characteristic can be used in large scale network, with some characteristic as that the number of vertices is fixed; number of edges is fixed, rewriting edges random.

3.2. The BA Model. The BA model is proposed by Barabási and Albert in their "Emergence of scaling in random networks" in 1999 (by Science) [27]. The BA model should meet two conditions: at first, the graph is opened and new vertices should continue to be added to the system; secondly, the attachment of the edges has the characteristic of preferential connectivity. So, the degree of vertices with rich-get-richer phenomenon can be detected easily in BA networks, and the growth process is shown as in Figure 3.

3.3. The Performances of Manufacturing Supply Chain Network. Now, let us trace the development of the manufacturing supply chain network from its origin. In Figure 1, at first, the vertex $M_{\text {in }}$ is new one and has no parts supplier, which means the core diagram only has candidate vertices with degree 1; then, some parts need to be produced from the suppliers, which means some edges should be added in the network. Which are the next vertices to produce the parts? It may be decided by random at the first time, the following selections maybe select other vertices different from the first vertices; perhaps the new selection is more efficient than the first one. Then, a most efficiency route arrived; the follow-up selections will tend to the same route to produce the parts; the selection will strengthen the ability of the notes in the chains, the abilities improvement of the vertices will firm the tendency to form fixed manufacturing supply chains. From the description above, we can see that the manufacturing supply chain network has some characteristics different from the BA model and WS model (see Figures 2 and 3).

First, both models suppose that the edges attached any two vertices without any repetition, but, in the manufacturing supply chain system, the edges maybe reduplicate, and it usually is repeated many times with the development of the manufacturing supply chain.

Second, in WS model, the attachment probability of new edge is fixed and comes randomly; in BA model, the attachment probability of new edge is be added along with vertices and with preferential connectivity. But those cannot meet the real supply chain network's request, and the new edges add into the network with preferential connectivity but do not need to add new vertices, so the number of vertices is fixed but the edges will keep increasing with preferential connectivity.
Third, the WS model and the BA model suggested that the edges probability of attachment is constant, but, in supply chain network, because of the limitation of production ability and the distance between them, the probability usually changes periodically. So, it needs a new model to meet the needs of manufacturing supply chains.

\section{The Core Model}

4.1. The Core Model of Manufacturing Supply Chain. In order to resolve the problems mentioned in WS model and BA model, our model maps the supply relationship network from Figure 1 to the core diagram in Figure 4; in Figure 4(a), it constituted by some vertices and some edges that the core has one input vertex and has $n$ selective supply vertices. The supply vertices may be defined as part suppliers; the edges may be defined as the costs between the input vertex/dominant firm $M_{\text {in }}$ and the special supply vertex. In the selecting process, the director of edges directs the collected to the supply vertices. If it needs to decide the parts supplier of vertex $M_{k}$, the core iterated on the vertex $M_{k}$, as shown in Figure 4(b).

Now, towards Figure 4(a), if $k_{i}$ is used to express the degrees set of vertex $i$, obviously, larger $k_{i}$ means more experience to produce the candidate parts. The edge $E_{i}$ is the supply relationships between the vertex $E_{i}$ to the supply vertex $M_{i}$, and lower value of $E_{i}$ shows that the transportation costs from vertex $M_{i}$ to the supply vertex $i$ are more cheap and means that vertex $i$ tends to be selected as the candidate unit. The object of production scheduling is to optimize the manufacturing systems so as to produce the parts using the minimize costs in the given during time, and it may be described as the following formula:

$$
O=\min \left\{O_{1}, O_{2}, O_{3}, \ldots, O_{n}\right\}, \quad(0<i<n) .
$$

Therefore, $O_{i}$ is the cost of vertex $i$.

4.2. The Vertex Probability Distribution in Manufacturing Supply Network. In order to describe the growing process of the manufacturing supply network, we supposed it satisfied the following 4 assumptions.

(1) The number of vertices in the network is fixed as $N$.

(2) It does not allow the edges' start and end to join the same vertices.

(3) The edges of network may grow freely only with preferential connectivity.

(4) The probability of changes meets a special function discussed next.

Supposing the core has $m_{0}$ edges initially, now $m(m<N)$ new edges should be added into the core diagram every fixed time interval $t$. and the attachments should select the vertices with biggest probability. After time interval $t$, the edges in the network will be $m_{0}+m t$ edges.

The first factor to be considered is the degree of vertex; it means the truth, cooperation times, or selection history. 


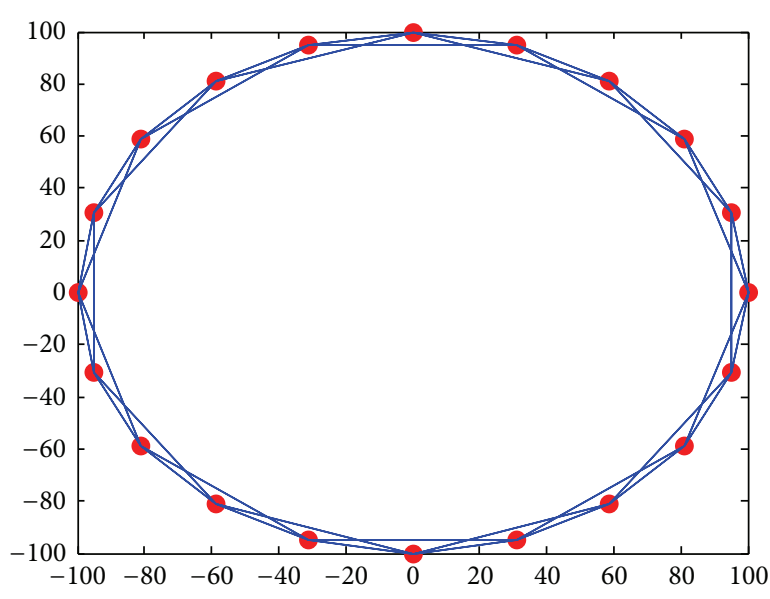

(a) $p=0$

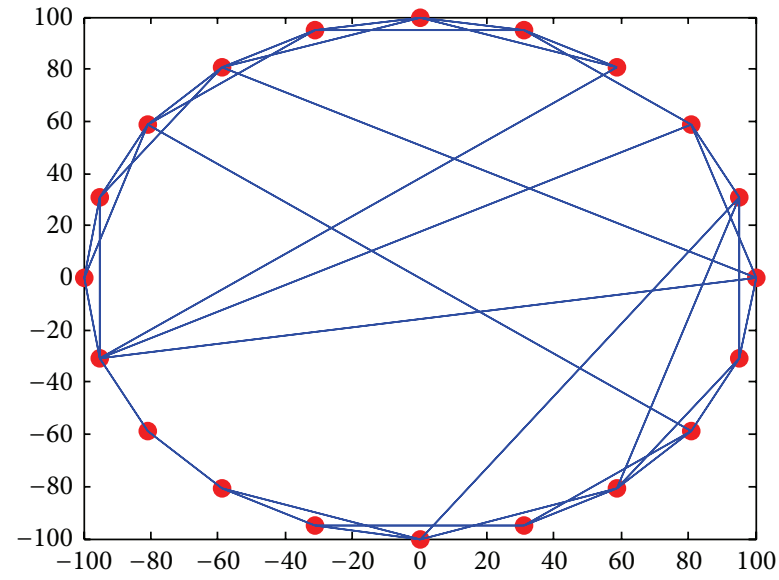

(b) $p=0.2$

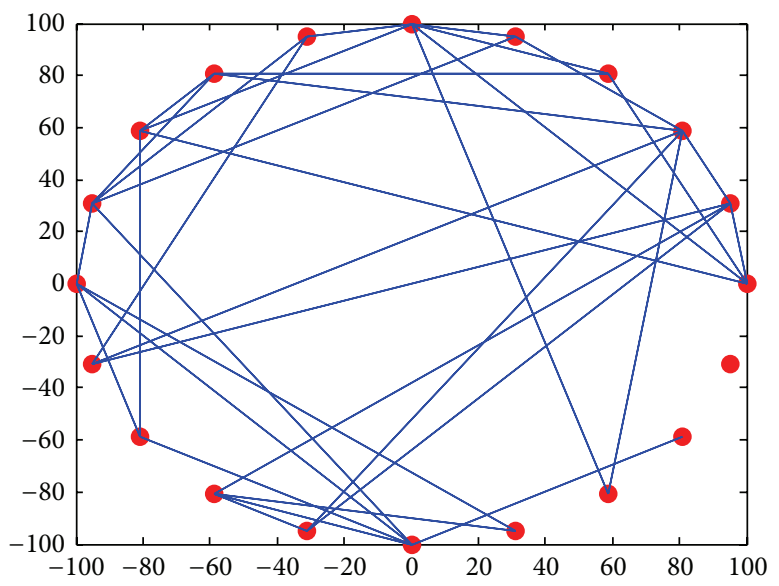

(c) $p=1$

Figure 2: The WS model.

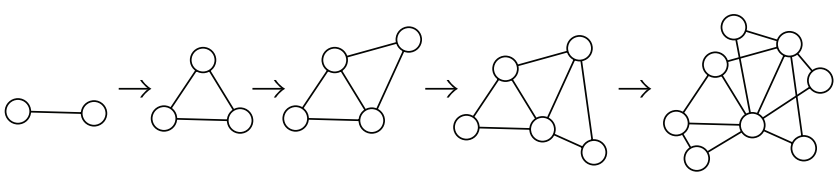

Figure 3: The growth of BA model.

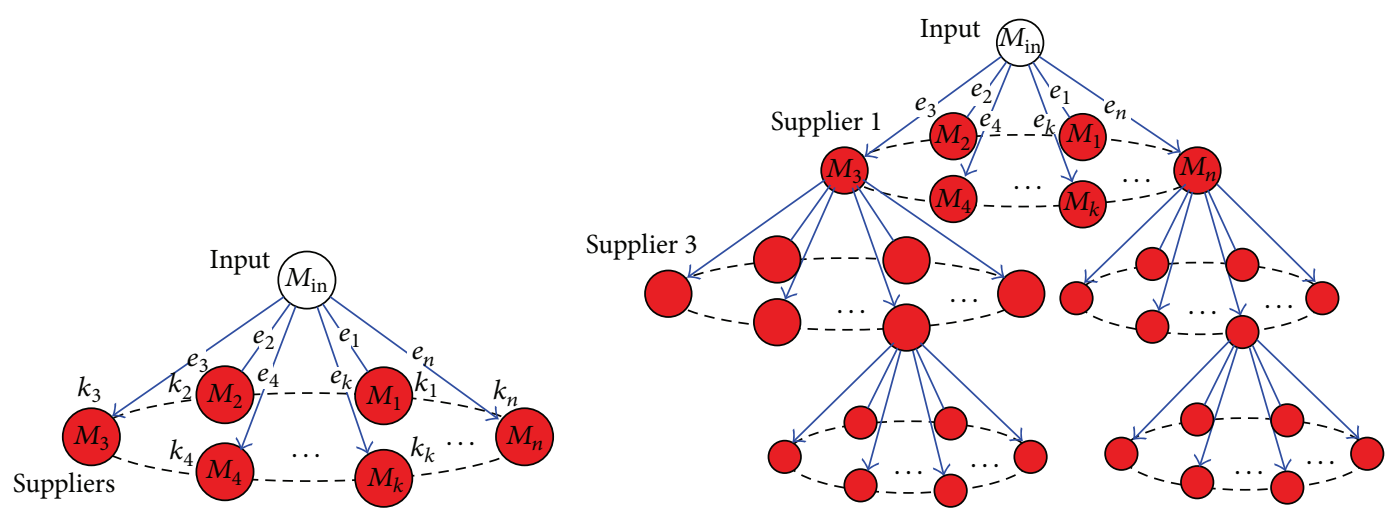

(a)

(b)

FIgURE 4: The core model. 
Obviously, the selection process is a binomial distribution function, as in the following formula:

$$
p\{X=t\}=k_{i} .
$$

The normalized result is the following formula:

$$
p_{i}=\frac{k_{i}}{\sum_{j=1}^{N} k_{j}} .
$$

However, the degree can not involve all the factors. It is only an experiment index; a bigger degree means the supplier has more experiment of operation, or it has more relation resources or skills. The edges rate should to be taken into consideration, and it is a cost index; it is to be decided by such as transportation costs of the parts, ready resources, and other costs. So, the relationship between the vertices degree and the edges rates should be taken into consideration. The preresearch shows that it is a linear function if only it is taken into consideration one factor of the vertex degree or the edges rates individually. Toward the vertex, the vertex degree and the edges rates are a binomial distribution; the probability distribution meets the function as in formula

$$
p\{X=i\}=k_{i}^{\tau} r_{i}^{1-\tau}, \quad(0 \leq \tau \leq 1) .
$$

The normalized results may be expressed as

$$
p_{i}=\frac{k_{i}^{\tau} r_{i}^{1-\tau}}{\sum_{j=1}^{N} k_{j}^{\tau} r_{j}^{1-\tau}}, \quad(0 \leq \tau \leq 1),
$$

where $k_{i}$ is the degree of vertex $i$, it may be decided as the operation times, and it may be obtained by computing the indegree; hence, $k_{i}$ may be computed as the following formula:

$$
k_{i}=\sum_{j=1}^{t} k_{\mathrm{in}-i},
$$

where $r_{i}$ is the rate of the attachment, $E_{i}$ means the costs attaching vertex $i$, and the affecting factor includes the diverting and other costs. Then, $r_{i}$ is

$$
r_{i}=\frac{1}{E_{i}},
$$

where $\tau$ is the adjustable parameter between $k_{i}$ and $r_{i}$, and it make it easier to adjust the vertices' degree and the edge's rates.

Formula (5) gives us a quantitative method to compute the probability distribution of suppliers at a time point. Each supplier has different calculating result and the results will change along with time because $k_{i}$ changes with the time.

If the time is unlimited, the parts supply chain plan tends to the most effective route, and other suppliers have no chances to obtain the orders. So, the operation cost is

$$
C_{\min }=\sum_{j=1}^{N} C_{\operatorname{Min}-i}, \quad(t \Gamma \leq T) .
$$

$i$.

Therefore, $C_{\mathrm{Min}-i}$ is the minimizing vertex's cost of vertex

On the contrary, if the time is very urgent, the time should exceed the shortest time request so as to finish all the parts of the batch. Maybe, the cost is the largest one:

$$
C_{\max }=\sum_{j=1}^{N} C_{i}, \quad\left(t \Gamma=\frac{T}{n}\right) .
$$

Therefore, $\sum_{j=1}^{N} C_{i}$ means all of the suppliers should work regardless of its inefficiency.

Usually, the optimal plan is between the two extreme cases, which means the operation tending to some effective suppliers and other suppliers may allocate fewer amounts of orders.

\section{Simulation Study}

Now, let us study the core model in simulation to check it. In our experience, the rate of edges (the reciprocal of transportation costs) came from random number between 0 and 1; each vertex has initial degree of 1 .

5.1. The Growth Process of Core Model. The growth of core is studied first in our experiment, and the results are shown in Figures 5 and 6.

Where the adjustable parameter of degree and edge is $\tau=$ 0.1 , the rates of edge come from random number; the vertex's number is 20 , and the number following the vertex name in Figure 5 is the vertex' degree.

From Figure 5, we can see that, with new edges added into the core model and the degree of core growing with the time, some vertices tend to grow, but other vertices' degree keeps constant. M6, M8, and M12 have the greatest degrees while degree $=1000$, that means those suppliers may keep lowest costs, and they are the best selections. On the contrary, the degrees of M1, M2, M4, M5, M7, M9, and M20 are 1 or 2, which means those suppliers have seldom chances to cooperate with the center vertex $M_{\text {in }}$.

5.2. The Degree Distribution of the Core Model. The degree distribution of growing process is shown in Figure 6: it shows that the key suppliers have a small number, but those vertices supplied a large number of parts; on the contrary, a large number of other vertices only supplied few parts (Figures 6(a) and 6(b)). The number of suppliers and the numbers of vertices in a core show a power law, vertex with rich degree becomes richer (Figures 6(c) and 6(d)), and the reality is almost like it. If the supplier has no chance to attend the cooperation in the earlier time, it needs to have a much lower cost to attend the core later; the cooperation of core is decided by lower cost and more trust.

Figure 7 shows the cooperation tendency chart in the core: the suppliers in higher degree (Figure 7(a)) or hot color (Figure 7(b)) mean the supplier has closer cooperation relationship with the core center vertex.

Figure 5 shows the cooperation tendency chart in the core: the suppliers in higher degree (Figure 5(a)) or hot 


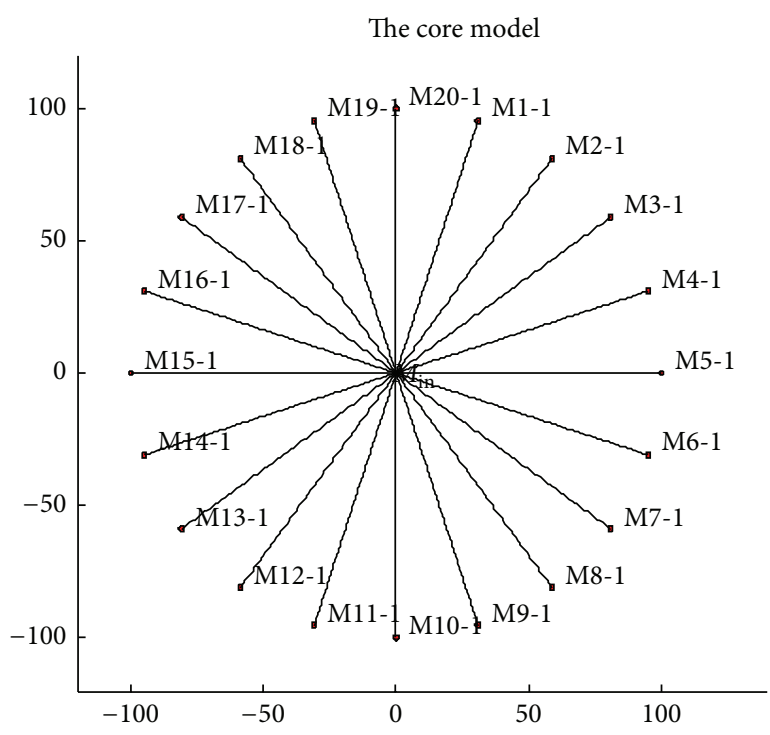

(a) Initial status

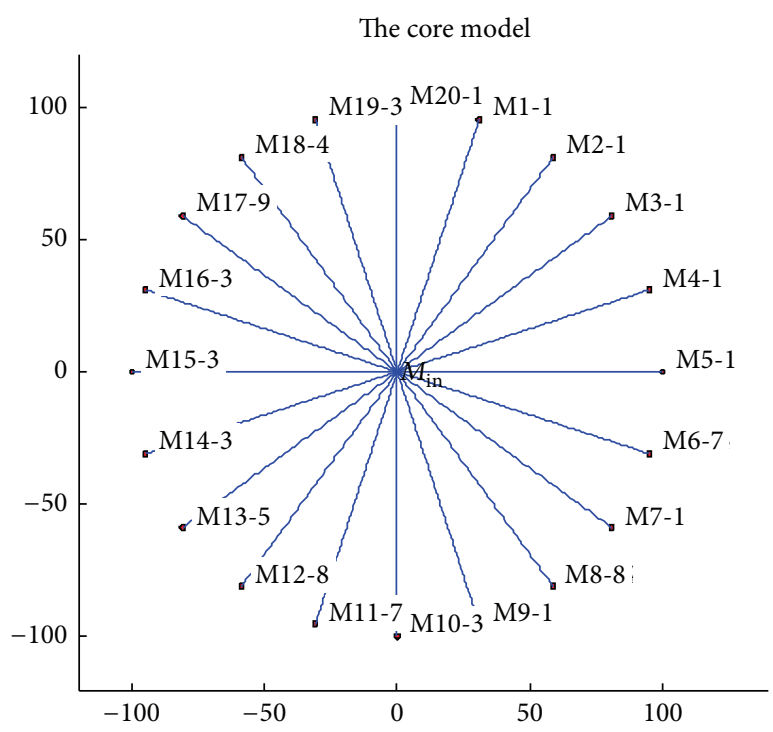

(c) Degree $=40$

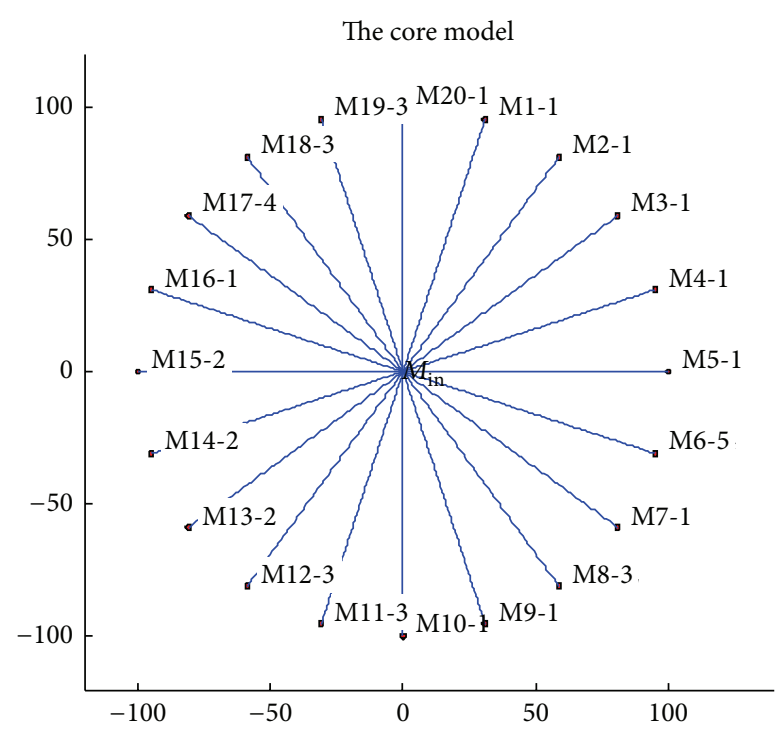

(b) Degree $=30$

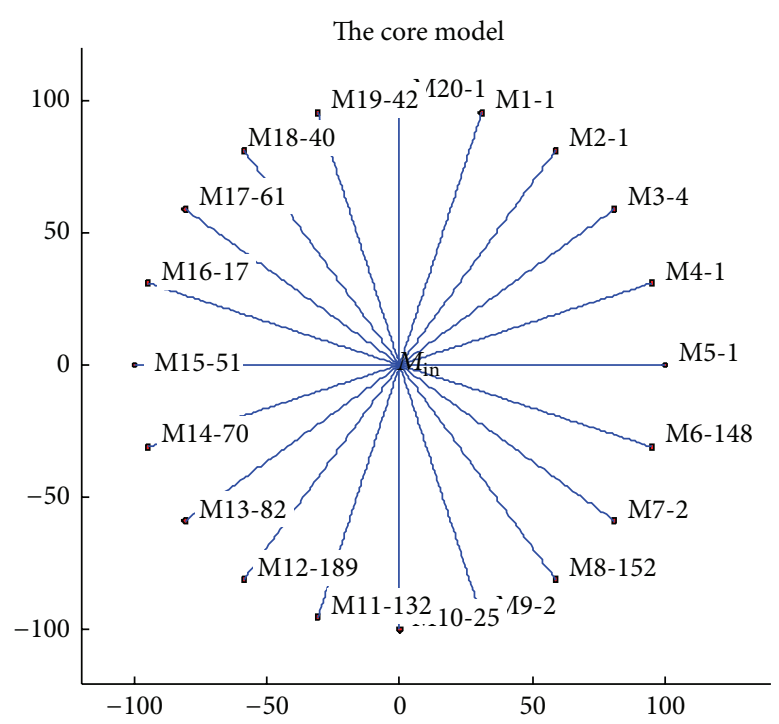

(d) Degree $=1000$

Figure 5: The growth of the core.

color (Figure 5(b)) mean the supplier has closer cooperation relationship with the core center vertex.

\subsection{The Impact of Parameters}

5.3.1. The Impact of Edge's Rate. Formula (5) shows that the edge's rate is one of the key factors for the core. The edge's rate comes from random number in our experiments above, and it affected the core chart which tends to smooth. What will happen if the edge's rate keeps constant? The experiment results show in Figure 8.

It shows that the degree distribution is a single peak function when the rates of edge are constant; it is obviously different from the rates of edge which are not constant. It may be explained from formula (5), while the rates of edge are constant means that the probability of vertex is only decided by the degree; once a vertex has a bigger degree than other vertices, the vertex's probability will be the biggest one in the core; other vertices have no chance to have the new edge.

5.3.2. The Impact of Adjustable Parameter. The adjustable parameter $t$ adjusts the importance of vertex's rate and the degree; it can impact the selection of new edge's attachment. Figure 9 shows the action of adjustable parameter $t$ from $t=0$ to $t=1$. While $t=0$, the degree does not act on any action according to formula (5); the degree of the core is a random function, and the difference of vertex degree is wave in a narrow range (the wave motion is between 30 and 45 while $t=0$, shown in Figure 9(a)); while $t=1$, the edge's rate does not take action, and only one vertex degree keeps 


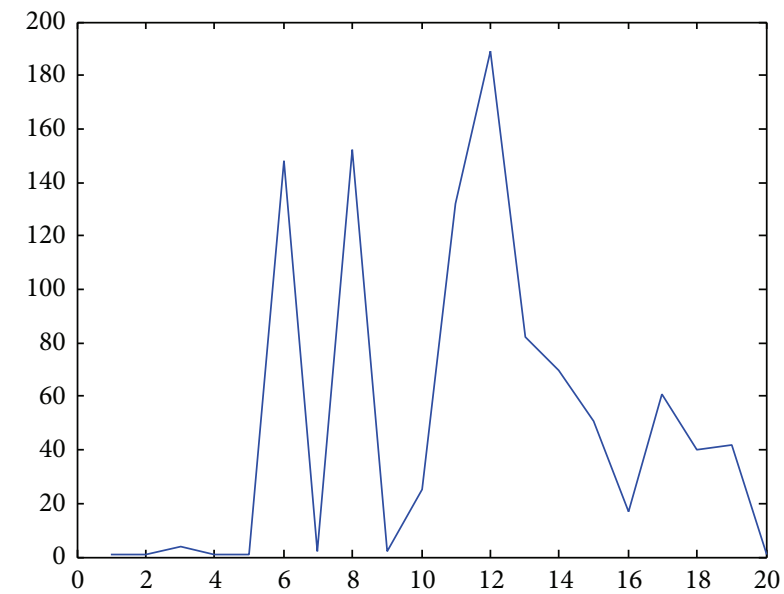

(a)

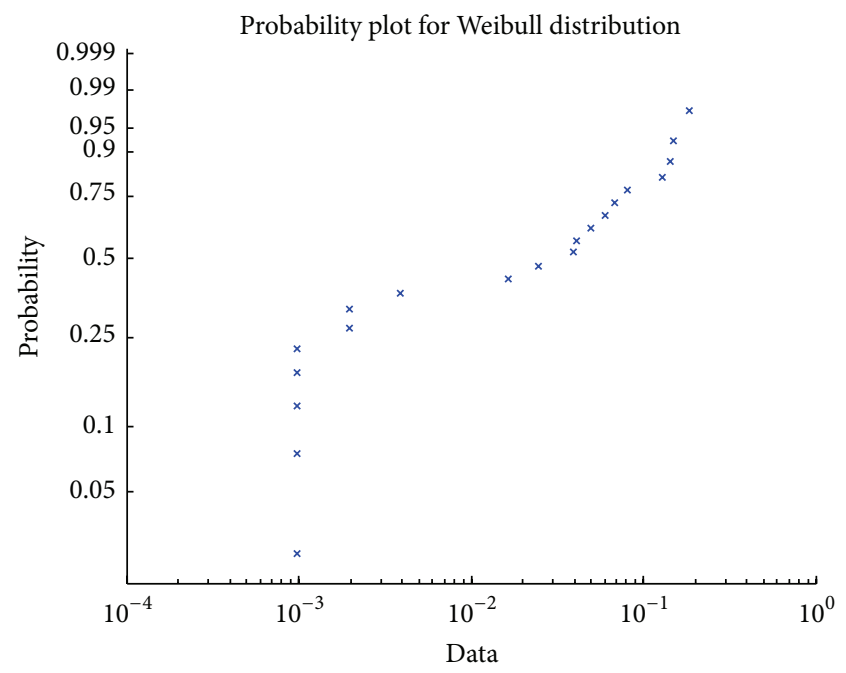

(c)

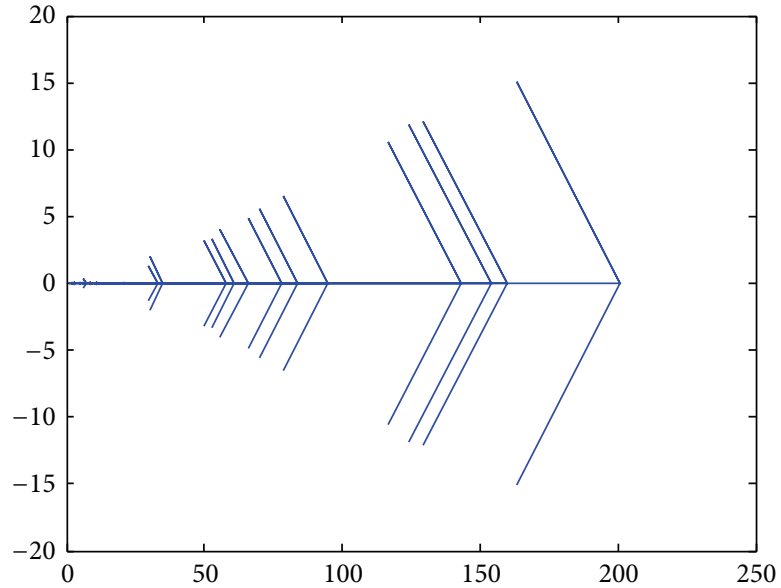

(b)

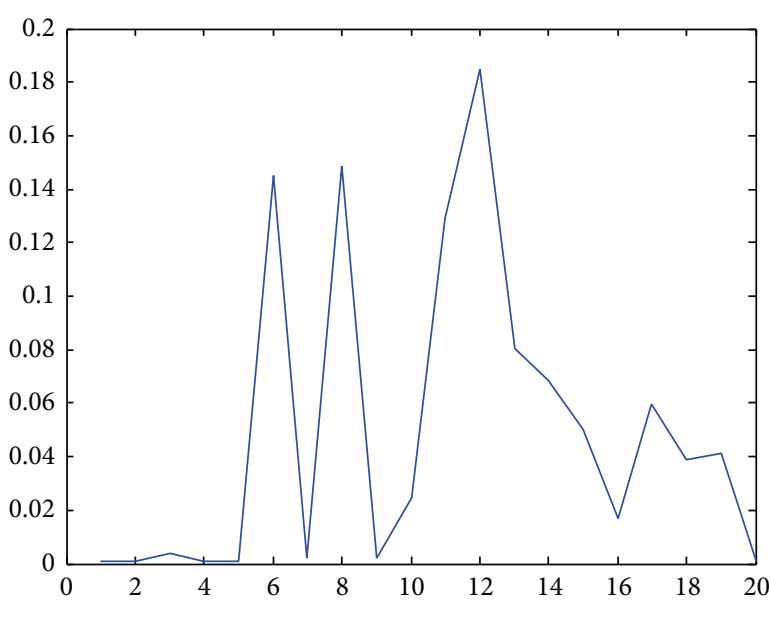

(d)

Figure 6: The degree distribution of the core while time $=1000$

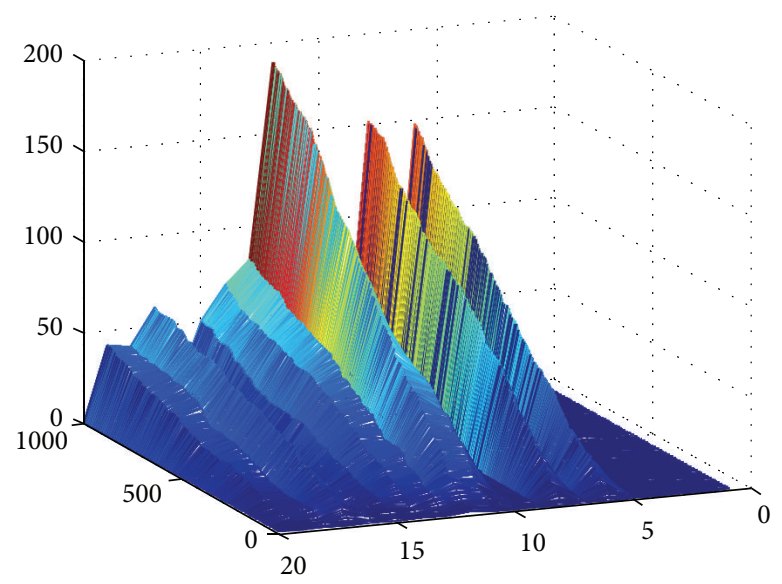

(a)

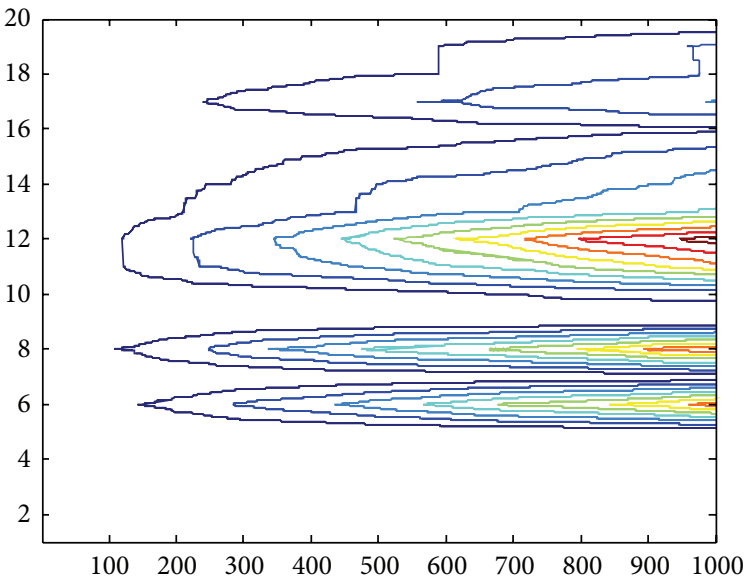

(b)

FIGURE 7: The cooperation relationship and tendency. 


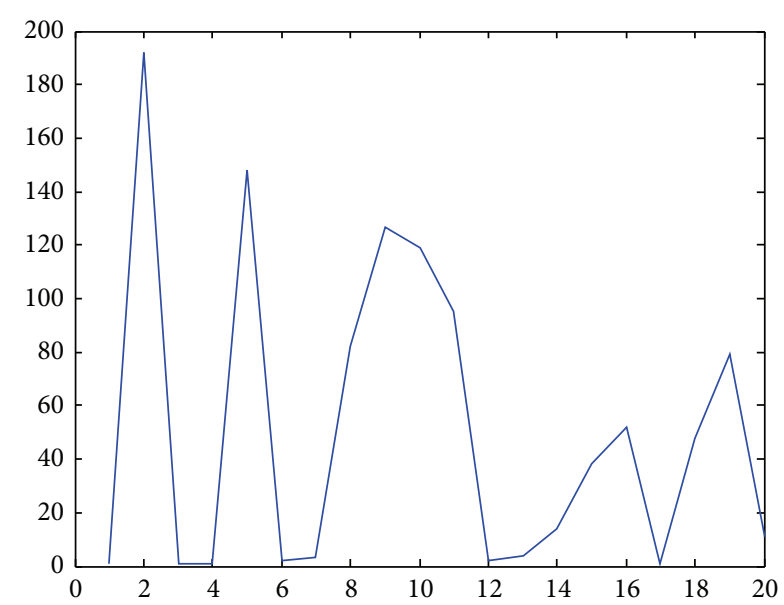

(a) The rates of edge are constant

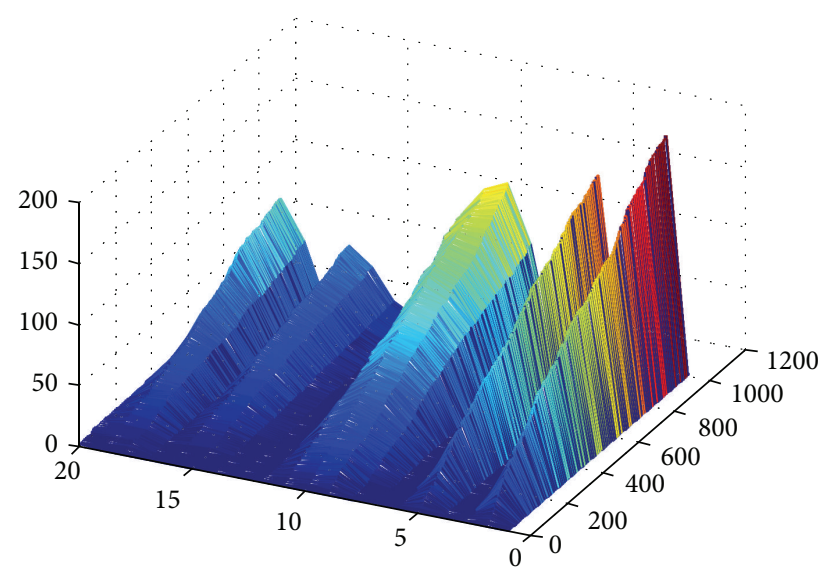

(c) The rates of edge are constant (3D)

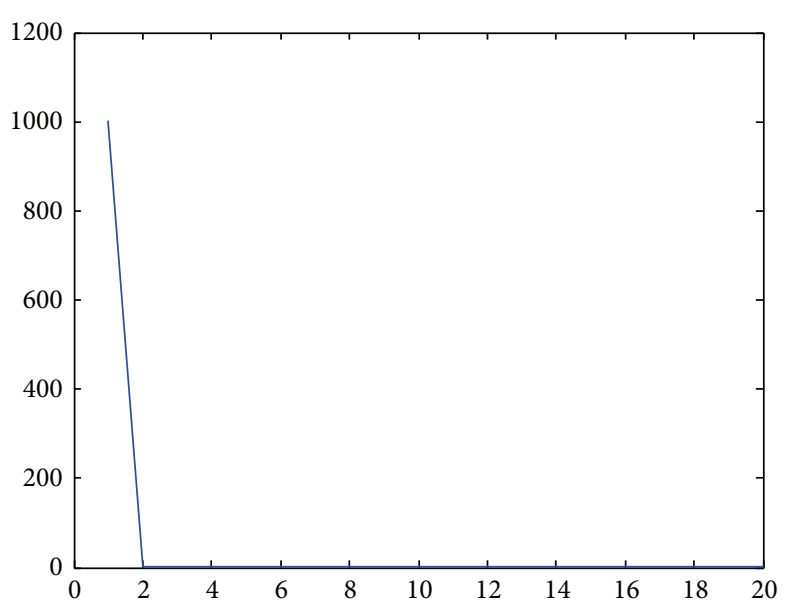

(b) The rates of edge are not constant

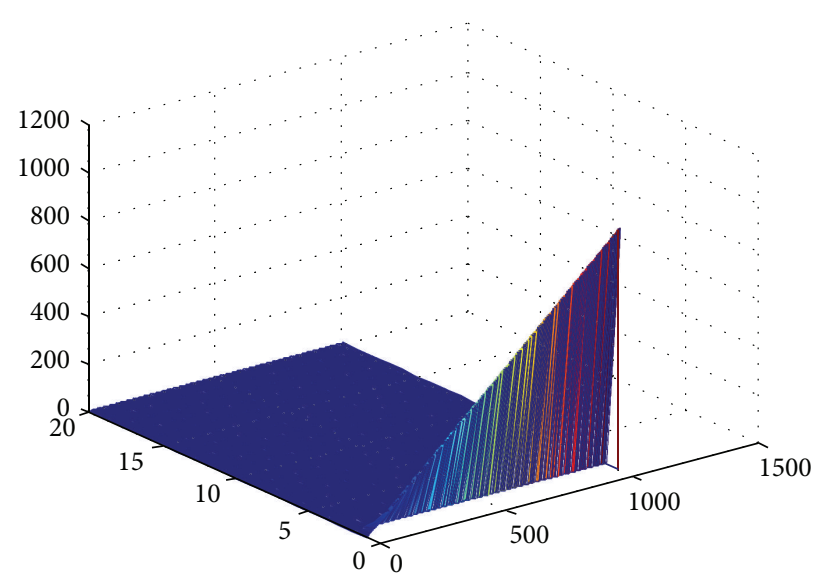

(d) The rates of edge are not constant (3D)

FIgURE 8: The impact of edge's rate.

increasing. With the value of $t$ increasing, the wave motion of vertex's degree becomes more and more wider (the wave motion is amplified between 20 and 50 while $t=0.01$, shown in Figure 9(b); between 1 and 200 while $t=0.1$ in Figure 9(c); between 1 and 350 while $t=0.2$ in Figure 9(d); between 1 and 1000 while $t \geqslant 0.5$ in Figures 9(e) and 9(f)). It also shows that degrees of vertex tend to difference, and the amount of suppliers attending to supply chain becomes more and more smaller; only one supplier supplies the parts while $t \geqslant 0.5$.

5.3.3. The Impact of Time/Experience. Figure 10 shows the growth process and tendency of the core with the time; the supply relationship is very chaotic at first, but it will tend to become different with the development of core; the supply relationship of the core tends to differentiation and stablility after a long time.

5.3.4. The Results of the Simulations. The simulations show that the supply chain is a power law network, and the selecting amount tends differently with the time. A little amount of vertices supply the most amount of parts; on the contrary, most of the vertices have little chances to attend the supply chain, and the supply relationship is the effect of Matthew; on the other hand, if a supplier improved their product and reduced the cost of parts, they have the chance to attend the supply chain network. So, the supply chain network is dynamic and clustered.

Formula (5) shows the directions of how to improve the chance of attending the supply chain: the first way is that the parts supplier keeps a closer relationship to the core firms in the network, which means that there is a larger $k_{i}$; another way is to keep a lower cost, which means that the supplier should reduce the cost of the parts, such as sale of lower parts price or producing the product locally (to reduce the transportation cost).

The simulations also show the difference between the model proposed in the paper and the traditional model: our model disclosed the running principle of the supply chain and gives the ways to how to improve the chance to obtain the orders, so it is a novel and practical method to analyze the supply chain.

\section{Case Analyses}

6.1. The IT Manufacturing Supply Chains Development at Chongqing China. The IT manufacturing industry of 


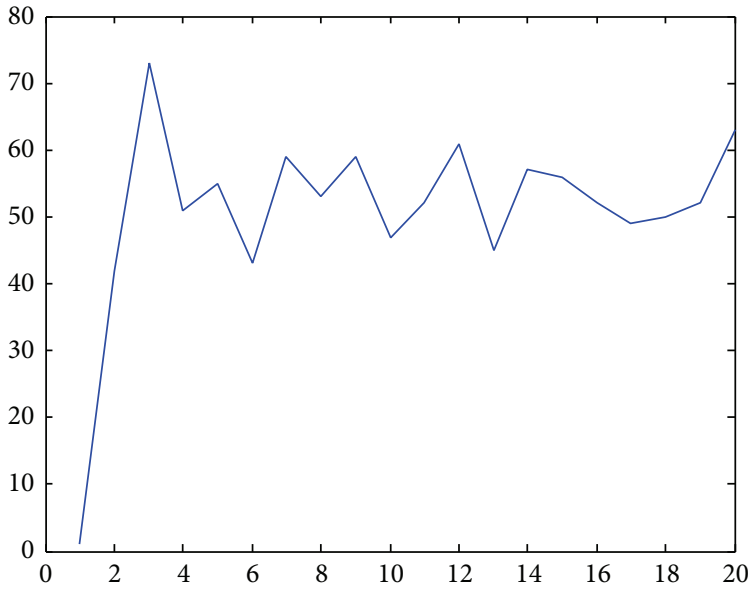

(a) $\tau=0$

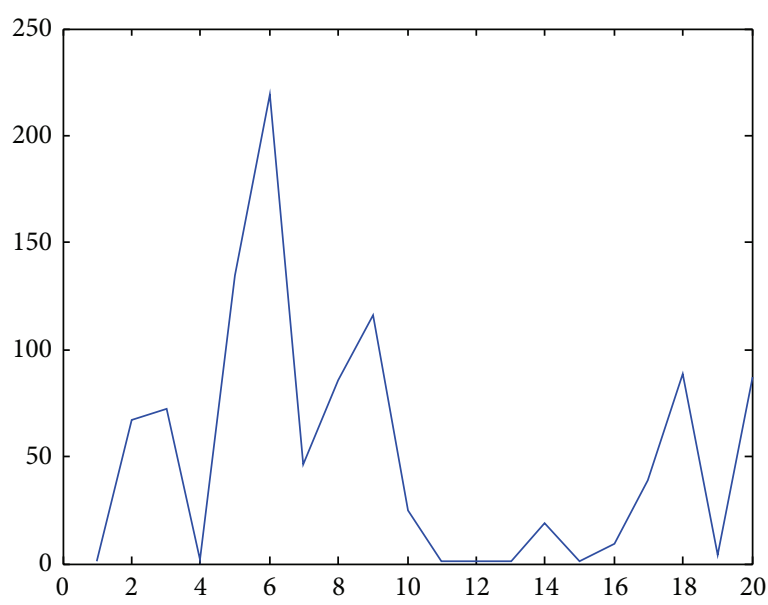

(c) $\tau=0.1$

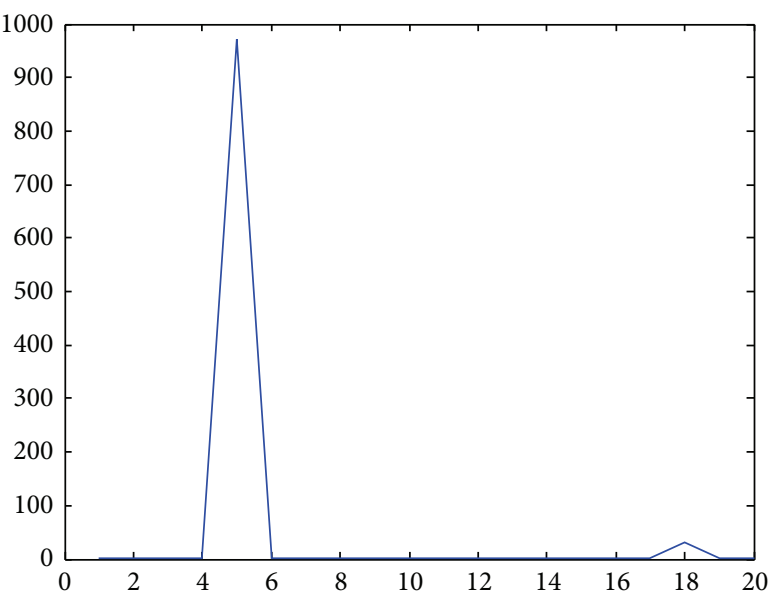

(e) $\tau=0.5$

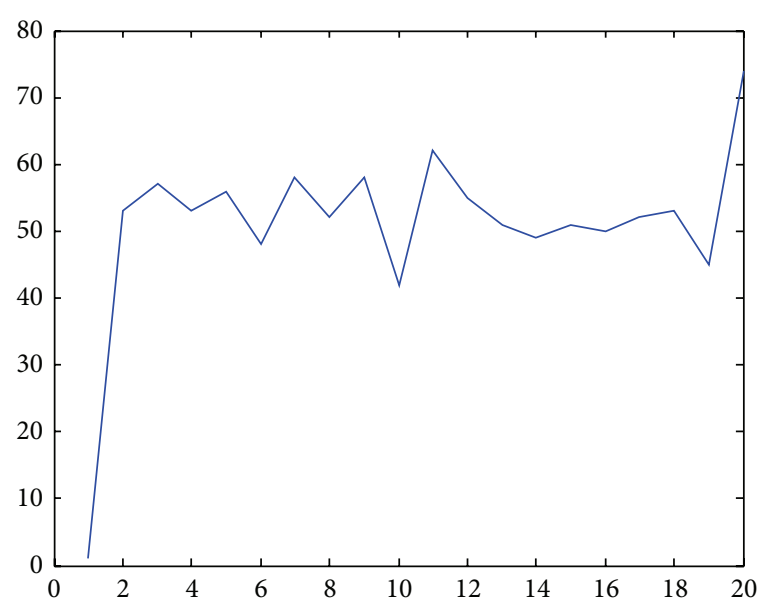

(b) $\tau=0.01$

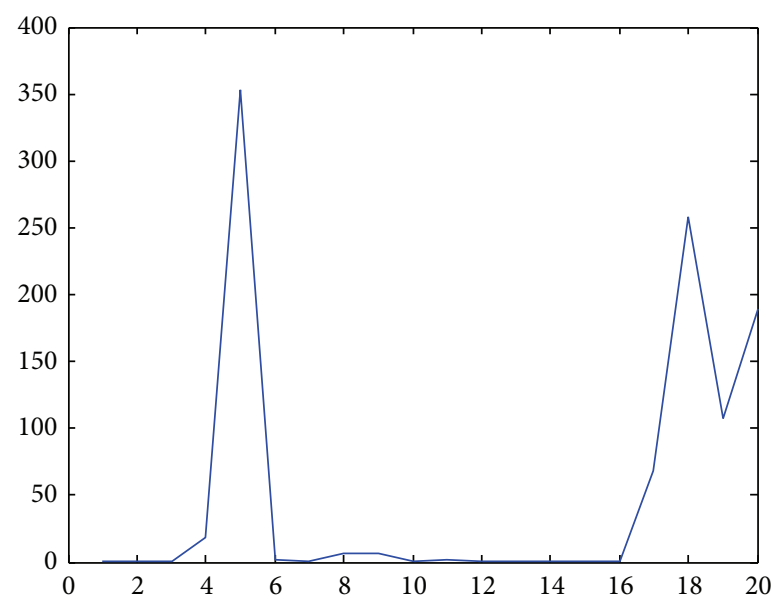

(d) $\tau=0.2$

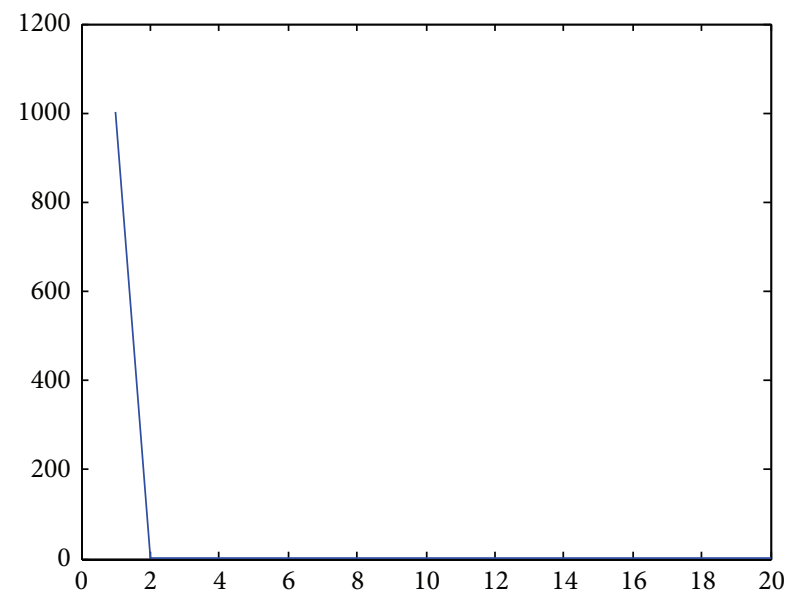

(f) $\tau=1$

FIgURE 9: The impact of adjustable parameter.

Chongqing China was very weak at 2000, but it had a rapid expansion while Hewlett-Packard (Chongqing) Co., Ltd, and Acer (Chongqing) Co., Ltd, began to produce the notebook computer in recent years and the notebook computer accounts for one-fifth of global production $[37,38]$.
Why did it expand so quickly? It clustered 5 large computer enterprises, 6 large foundries, and 817 parts manufacturers in Xiyong Chongqing till February 11, 2014, and the industry gathering circle is about 1 hour drive. One very interesting phenomenon is that these companies are new plants 


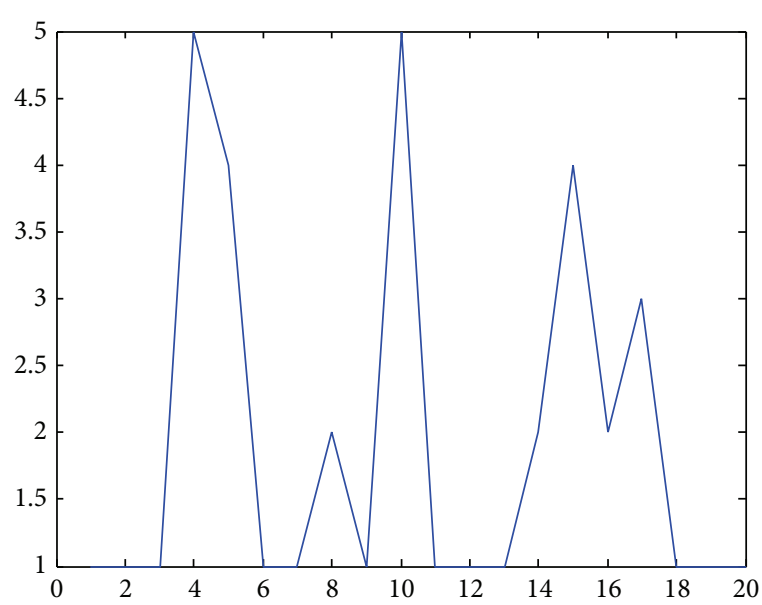

(a)

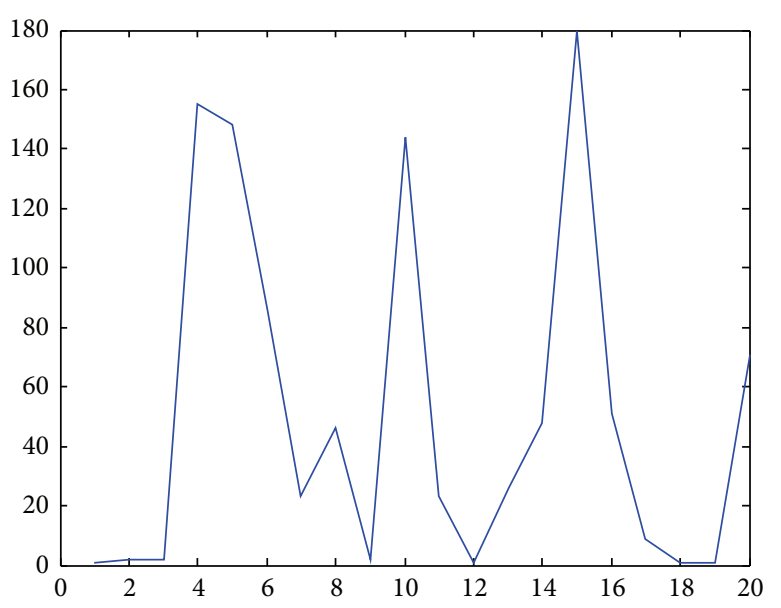

(b)

Figure 10: The growth process and tendency of the core.

following the large enterprises such as HP, Acer, and Cisco. The foundries and parts manufacturers built new production plant in Chongqing in order to decrease the transportation costs to the lowest level, so they have the lowest, calculated from formula (5); the lowest gained the biggest probability distribution, and they will obtain the greatest opportunities for cooperating with the large computer enterprises, and the industry aggregation phenomenon proved their action in practice.

6.2. Jiangmen Hi-Tech Development Zone. Jiangmen Hi-tech Development Zone began at 1992 [39]; it is one of the Hitech development zones of China. But the park was one of the worst Hi-tech development zones in China before 2010. It introduces itself as being able to serve for many industries, such as LED, advanced and other industries, but only a few enterprises grow up in the zone. Why is that? Because there almost are no large enterprises, and the products produced here need to be sold to the enterprises far away from there, which means the product costs have higher than other part suppliers; in other words, it has least probability distribution. In order to develop better, Jiangmen Hi-tech Development Zone replaned the industrial layout and direction and set up three professional parks, such as auto parts professional park; FAW Volkswagen and other auto manufacturers built their factories in the park; it speeded up all the auto parts development, so the professional park developed very fast in recent years; Jiangmen Hi-tech Development Zone is an important professional park in south China now.

\section{Summary}

Aiming at the three difficulties of classical complex network theories to resolve the optimal selection of parts suppliers, a core model is proposed in the paper after reviewing famous BA model and WS model; it maps the parts supply relationships of manufacturing supply chain as a repeatable core. A vertex's probability distribution formula is put forward; it mainly involves the edge's rate and vertex's degree. Some simulation studies, such as the growth of core, the degree distribution characteristics, and the impacting of parameter experiment, were carried out. At last, two cases were set out to prove the correctness in the paper. The core model can be used to resolve some difficulties-with repeating edge attachment, fixed vertices number but increasing edges with preferential connectivity, and flexible edges probability.

It did not consider the interactions of other cores and the consistency of costs in our experiments; the calculating results may be a little deviated, and we plan to resolve those problems in next steps.

\section{Conflict of Interests}

The authors declare that there is no conflict of interests regarding the publication of this paper.

\section{Acknowledgments}

This research is supported by the Natural Sciences Fund of China (Grant no. 51275547) and the Natural Science Fund Projects in Chongqing (Grant no. cstc2012gg-yyjs40019, CSTCjjA1481).

\section{References}

[1] C. P. Holland, "Cooperative supply chain management: the impact of interorganizational information systems," The Journal of Strategic Information Systems, vol. 4, no. 2, pp. 117-133, 1995.

[2] S. P. Sarmah, D. Acharya, and S. K. Goyal, "Buyer vendor coordination models in supply chain management," European Journal of Operational Research, vol. 175, no. 1, pp. 1-15, 2006.

[3] P. Kelle and A. Akbulut, "The role of ERP tools in supply chain information sharing, cooperation, and cost optimization," International Journal of Production Economics, vol. 93-94, pp. 41-52, 2005.

[4] M. Nagarajan and G. Sošić, "Game-theoretic analysis of cooperation among supply chain agents: review and extensions," 
European Journal of Operational Research, vol. 187, no. 3, pp. 719-745, 2008.

[5] P. Fiala, "Information sharing in supply chains," Omega, vol. 33, no. 5, pp. 419-423, 2005.

[6] R. C. Savaskan, S. Bhattacharya, and L. N. van Wassenhove, "Closed-loop supply chain models with product remanufacturing," Management Science, vol. 50, no. 2, pp. 239-252, 2004.

[7] S.-H. Ma and X.-Y. Chen, "The study for elements and characters of integrated logistics capability," Chinese Journal of Management, vol. 1, no. 1, pp. 107-111, 2004.

[8] S.-J. Xu and S.-H. Ma, "A study on trust crisis between inter-firm in supply chain in china," Computer Integrated Manufacturing System, vol. 8, no. 1, pp. 51-53, 2002.

[9] P. E. Love, Z. Irani, E. Cheng, and H. Li, "A model for supporting interorganizational relations in the supply chain," Engineering Construction and Architectural Management, vol. 9, no. 1, pp. 215, 2002.

[10] L. Liang, F. Yang, W. D. Cook, and J. Zhu, "DEA models for supply chain efficiency evaluation," Annals of Operations Research, vol. 145, pp. 35-49, 2006.

[11] M. Leng and A. Zhu, "Side-payment contracts in two-person nonzero-sum supply chain games: review, discussion and applications," European Journal of Operational Research, vol. 196, no. 2, pp. 600-618, 2009.

[12] Q. Zhu, J. Sarkis, and K.-H. Lai, "Confirmation of a measurement model for green supply chain management practices implementation," International Journal of Production Economics, vol. 111, no. 2, pp. 261-273, 2008.

[13] G. P. Cachon and P. H. Zipkin, "Competitive and cooperative inventory policies in a two-stage supply chain," Management Science, vol. 45, no. 7, pp. 936-953, 1999.

[14] J. Sarkis, "A strategic decision framework for green supply chain management," Journal of Cleaner Production, vol. 11, no. 4, pp. 397-409, 2003.

[15] Z. Huang, S. X. Li, and V. Mahajan, "An analysis of manufacturer-retailer supply chain coordination in cooperative advertising," Decision Sciences, vol. 33, no. 3, pp. 469-494, 2002.

[16] M. E. Ferguson, "When to commit in a serial supply chain with forecast updating," Naval Research Logistics, vol. 50, no. 8, pp. 917-936, 2003.

[17] A. Surana, S. Kumara, M. Greaves, and U. N. Raghavan, "Supply-chain networks: a complex adaptive systems perspective," International Journal of Production Research, vol. 43, no. 20, pp. 4235-4265, 2005.

[18] A. Gupta and C. D. Maranas, "Managing demand uncertainty in supply chain planning," Computers and Chemical Engineering, vol. 27, no. 8-9, pp. 1219-1227, 2003.

[19] D. Kim, S. T. Cavusgil, and E. Cavusgil, "Does IT alignment between supply chain partners enhance customer value creation? An empirical investigation," Industrial Marketing Management, vol. 42, no. 6, pp. 880-889, 2013.

[20] B. L. Connelly, D. J. Ketchen, and G. T. M. Hult, "Global supply chain management: toward a theoretically driven research agenda," Global Strategy Journal, vol. 3, no. 3, pp. 227-243, 2013.

[21] http://www.columbia.edu/cu/news/01/12/duncanWatts.html.

[22] http://www.cs.virginia.edu/oracle.

[23] http://www.oakland.edu/enp/erdpaths.

[24] P. Erdős and A. Rényi, "On the evolution of random graphs," Magyar Tudományos Akadémia Matematikai Kutató Intézetének Közleményei, vol. 5, pp. 17-61, 1960.
[25] D. J. Watts and S. H. Strogatz, "Collective dynamics of "smallworld” networks," Nature, vol. 393, no. 6684, pp. 440-442, 1998.

[26] D. J. Watts, “The "new' science of networks," Annual Review of Sociology, vol. 30, pp. 243-270, 2004.

[27] A.-L. Barabási and R. Albert, "Emergence of scaling in random networks," American Association for the Advancement of Science. Science, vol. 286, no. 5439, pp. 509-512, 1999.

[28] R. Albert and A.-L. Barabási, "Statistical mechanics of complex networks," Reviews of Modern Physics, vol. 74, no. 1, pp. 47-97, 2002.

[29] A. Gregoriades and A. Sutcliffe, "Workload prediction for improved design and reliability of complex systems," Reliability Engineering and System Safety, vol. 93, no. 4, pp. 530-549, 2008.

[30] D. Shi, Q. Chen, and L. Liu, "Markov chain-based numerical method for degree distributions of growing networks," Physical Review E, vol. 71, no. 3, Article ID 036140, 9 pages, 2005.

[31] D. Shi, L. Liu, S. X. Zhu, and H. Zhou, "Degree distributions of evolving networks," EPL (Europhysics Letters), vol. 76, no. 4, pp. 731-737, 2006.

[32] X. F. Wang, "Complex networks: topology, dynamics and synchronization," International Journal of Bifurcation and Chaos, vol. 12, no. 5, pp. 885-916, 2002.

[33] Z. Li and G. Chen, "Global synchronization and asymptotic stability of complex dynamical networks," IEEE Transactions on Circuits and Systems II: Express Briefs, vol. 53, no. 1, pp. 28-33, 2006.

[34] L. F. Y. Q. Q. Guoning and H. Zheren, "Universality analysis method of parts for product family based on complex network," Chinese Journal of Mechanical Engineering, vol. 11, article 014, 2005.

[35] C. Guorong, D. Juli, S. Jinliang, and Y. Ping, "Relationship network analysis of manufacturing system limited by business lines," TELKOMNIKA Indonesian Journal of Electrical Engineering, vol. 10, no. 6, pp. 1503-1509, 2012.

[36] M. E. J. Newman and D. J. Watts, "Renormalization group analysis of the small-world network model," Physics Letters A, vol. 263, no. 4-6, pp. 341-346, 1999.

[37] http://wjj.cq.gov.cn/cqgy/gygk/cqgyfzndbg/40451.htm.

[38] http://news.jrcq.cn/news/2014-02/11/1818.html.

[39] http://www.jip.gov.cn/default.html. 


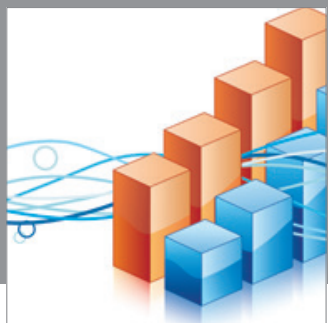

Advances in

Operations Research

mansans

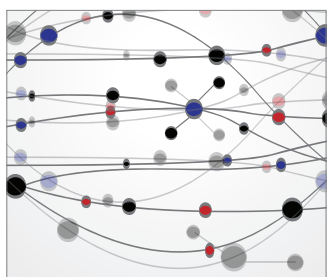

The Scientific World Journal
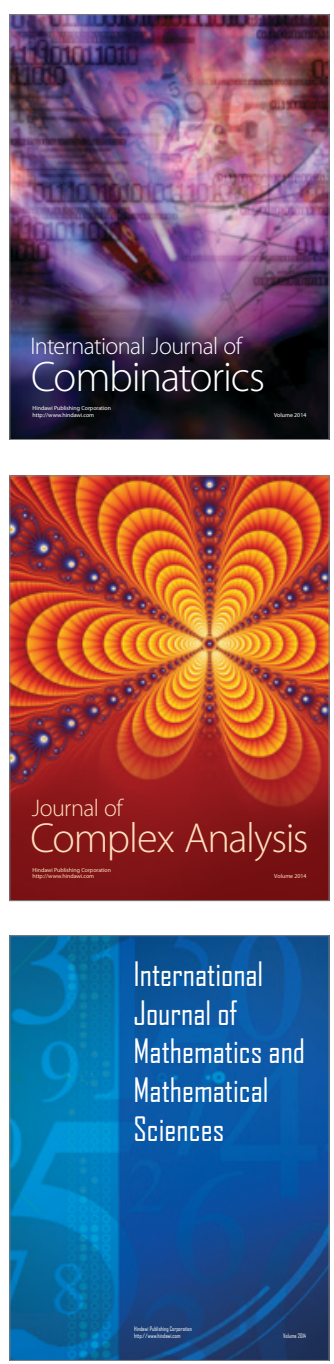
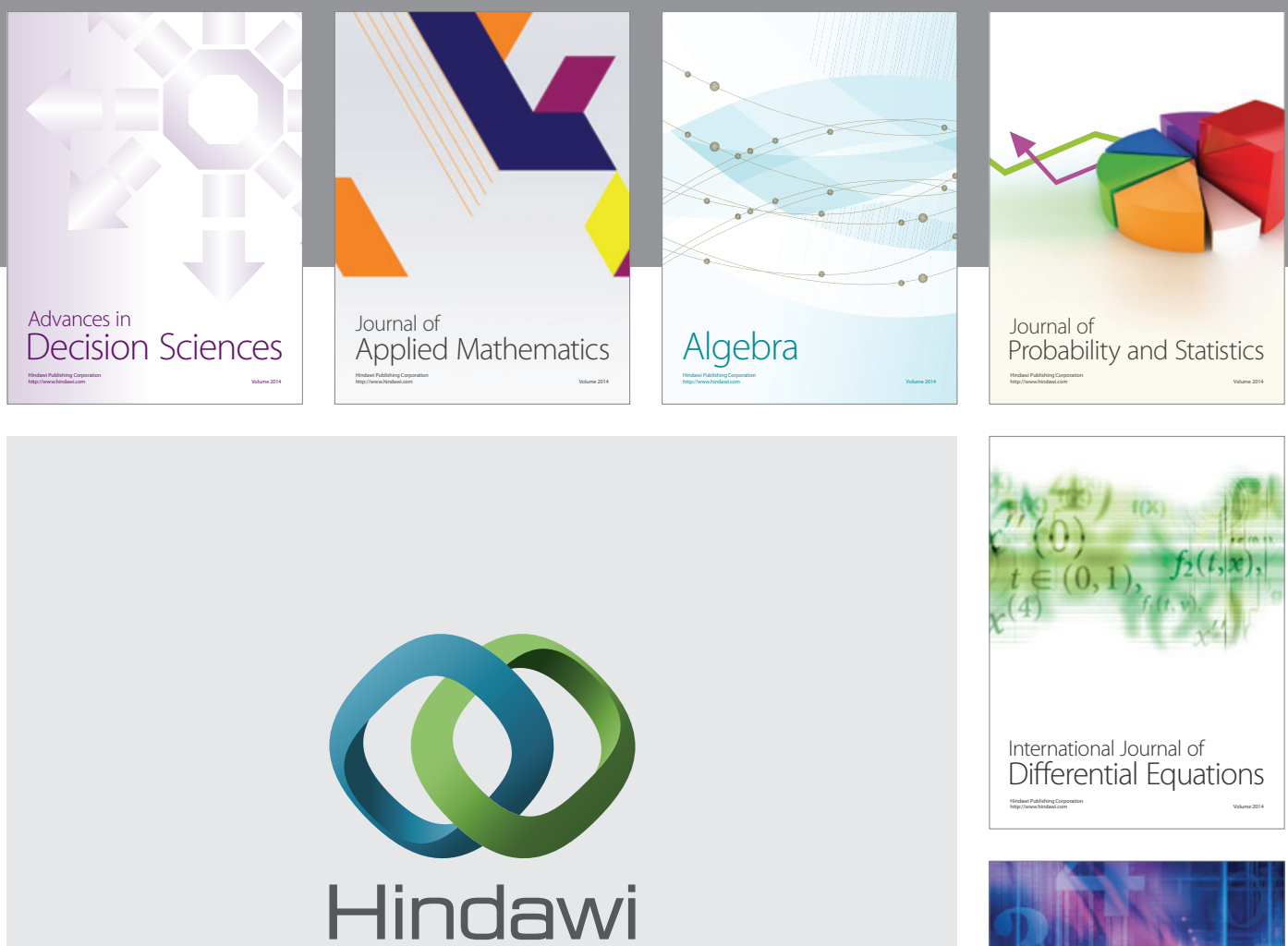

Submit your manuscripts at http://www.hindawi.com
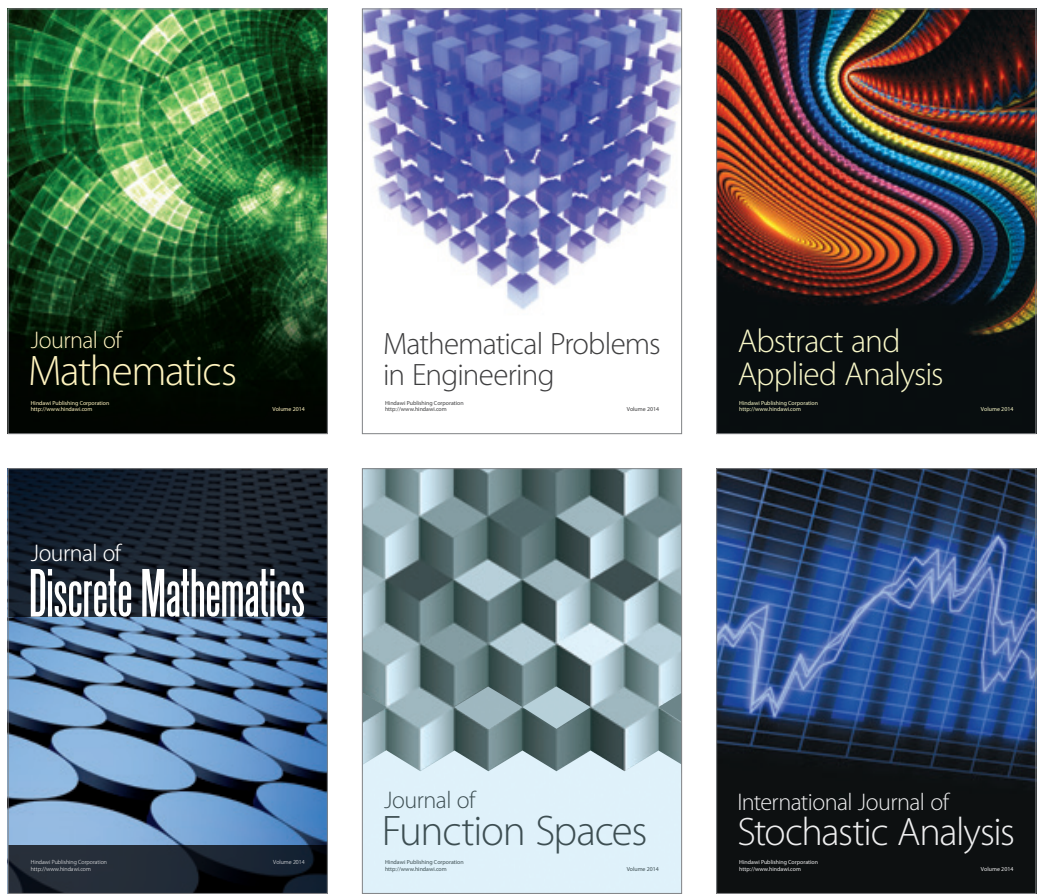

Journal of

Function Spaces

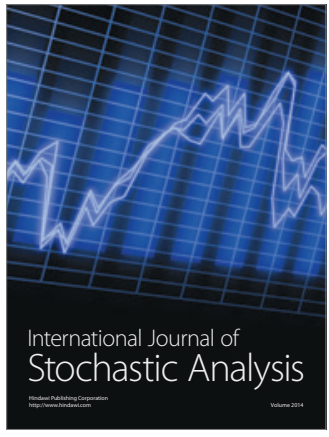

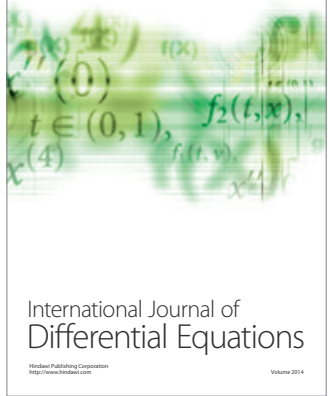
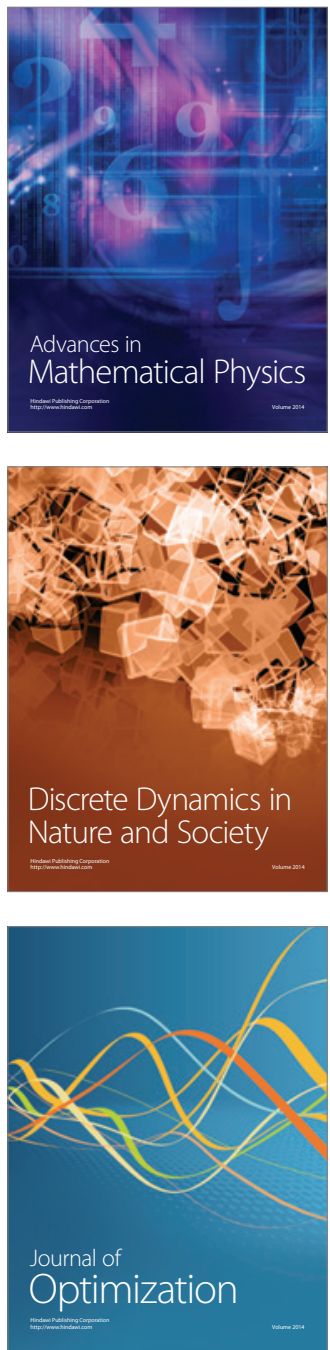